Accepted for publication 29/9/19:

Epstein, M., Söderström, M., Jirwe, M., Tucker, P. \& Dahlgren, A. (in press). Sleep and fatigue in newly graduated nurses - experiences and strategies for handling shiftwork. Journal of Clinical Nursing. 


\title{
Sleep and fatigue in newly graduated nurses - experiences and strategies for handling shiftwork
}

\begin{abstract}
Aims and objectives

This study explores newly graduated nurses' strategies for, and experiences of, sleep problems and fatigue when starting shiftwork. A more comprehensive insight into nurses' strategies, sleep problems, fatigue experiences and contributing factors is needed in order to understand what support should be provided.
\end{abstract}

Background

For graduate nurses, the first years of practice are often stressful, with many reporting high levels of burnout symptoms. Usually, starting working as a nurse also means an introduction to shiftwork, which is related to sleep problems. Sleep problems may impair stress management, and at the same time, stress may cause sleep problems. Previously, sleep problems and fatigue have been associated with burnout, poor health and increased accident risk.

Design and Methods

Semi-structured interviews were conducted with nurses $(\mathrm{N}=11)$ from four different Swedish hospitals and qualitative inductive content analysis was used. The study was approved by the Regional Ethical Review Board in Stockholm. The COREQ checklist was followed.

Results

Many nurses lacked effective strategies for managing sleep and fatigue in relation to shiftwork. Various strategies were used, of which some might interfere with factors regulating and promoting sleep such as the homeostatic drive. Sleep problems were common during quick returns, often due to difficulties unwinding before sleep, and high workloads exacerbated the problems. The described consequences of fatigue in a clinical work context indicated impaired executive and non-executive cognitive function.

Conclusion

The findings indicate that supporting strategies and behaviours for sleep and fatigue in an intervention for newly graduated nurses starting shiftwork may be of importance in order to improve wellbeing among nurses and increase patient safety.

Relevance to clinical practice

This study highlights the importance of addressing sleep and fatigue issues in nursing education and work introduction programmes in order to increase patient safety and improve wellbeing among nurses.

Keywords: shiftwork, sleep, fatigue, newly graduated nurses, patient safety 


\section{Introduction}

Approximately 20\% of all Swedish nurses experiences very high levels of burnout symptoms at some point during the first years of practice (Rudman \& Gustavsson, 2011). In addition to stressors that are evident for the whole nursing population, such as high workload, staff shortage and emotional demands (McVicar, 2003), newly graduated nurses are facing specific challenges associated with the adaptation to a new professional role, a phenomenon referred to as a transition shock (Duchscher, 2009). When developing methods to facilitate the nurse's transition from education into working life, a variety of stressors at both the organizational and individual level have to be considered (Sun, Ji, Zhou, \& Liu, 2019).

The stress response promotes adaptation through bodily and behavioural changes, but may have damaging effects if prolonged or repeated without sufficient recovery in between (McEwen, 2004). Previously, incomplete recovery has been suggested to mediate the relation between stressful working conditions and health impairment (Geurts \& Sonnentag, 2006). For many, starting working as a nurse also means an introduction to shiftwork, which inevitably affects opportunities for sleep and recuperation due to interference with the circadian and homeostatic regulation of sleep (Åkerstedt, 2003). Not surprisingly, sleep problems are more common among nurses working on shift schedules compared to nurses working regular day time (McDowall, Murphy, \& Anderson, 2017). In a cohort of Swedish nurses, subjective sleep quality was shown to decrease from the last semester of the education and during the first three years of employment (Hasson \& Gustavsson, 2010). Sleep problems and fatigue among nurses may threaten both the nurses' own health and patient safety (Hughes \& Rogers, 2004; McEwen, 2006).

\section{Background}

Sleep deprivation is a stressor for the brain and body (McEwen, 2006) and insufficient sleep has been identified as a main risk factor for clinical burnout (Söderström, Jeding, Ekstedt, Perski, \& Åkerstedt, 2012). At the same time, stress is known to negatively influence sleep (Linton et al., 2015). High workload and high perceived stress at work have been associated with heightened stress at bedtime and shorter sleep (Dahlgren, Kecklund, \& Åkerstedt, 2005). It is possible that sustained physiological activation partly explains the impact of stress and workload on sleep, but perseverative cognition is also likely to play a role (Brosschot, Gerin, \& Thayer, 2006).

Shiftwork in general is associated with sleep problems and fatigue (Kecklund \& Axelsson, 2016). A key issue is the timing of the shifts. Night shifts and early morning shifts have been associated with more sleep problems and fatigue, compared to evening shifts (Åkerstedt, 2003). Recent studies have shown that shift combinations involving so called 'quick returns', i.e. less than 11 hours between shifts, are associated with shorter sleep, impaired sleep quality, increased sleepiness and fatigue (Vedaa et al., 2015). The frequency of quick returns is also associated with difficulties unwinding (Dahlgren, Tucker, Gustavsson, \& Rudman, 2016). Two more or less ineluctable consequences of disturbed sleep are sleepiness and fatigue. Fatigue is a major safety hazard and has been associated with impaired performance, higher error rates and reduced safety (Dawson \& McCulloch, 2005).

Theoretical framework 
Given the vital role of sleep and recovery in the relationship between stress and development of illness (Geurts \& Sonnentag, 2006; McEwen, 2004; Söderström et al., 2012), effective strategies for sleep and recovery are hypothesised to be crucial in preventing the development of stress-related illnesses (Colombo \& Cifre Gallego, 2012). They are likely to be particularly important for newly graduated nurses who are exposed to a large number of stressors in their daily work at the same time as they are starting to work shifts. Strategies for managing fatigue are also of great importance, not least considering the potential impact on patient safety.

Aim

Little is known about the actual strategies for managing sleep and fatigue that nurses adopt when they start working shifts. Such knowledge, together with more comprehensive understanding of new nurses' sleep problems and the nature of their fatigue problems, is important in order to know which support (or interventions) nurses need when starting out in their new career. By focusing on newly graduated nurses and their challenges, appropriate support can be put in place before more serious problems arise. Thus, the aim of the current study was to explore the strategies used by newly graduated nurses for managing sleep and fatigue problems, identify which factors they experienced as contributing to sleep problems, and ascertain the nature of the fatigue problems that they experience. In this study, a newly graduated nurse is defined as a nurse in their first year of employment.

\section{Methods}

\section{Participants}

Eleven newly graduated nurses (ten women, one man) between 22 and 51 years old ( $M=$ 29.1, $S=8$ ) were included in the study. The nurses were recruited from four, university and county hospitals. The inclusion criterion was a maximum of one year's employment as a registered nurse. In Sweden, the education for registered nurses consists of about $60 \%$ theoretical education and 40\% clinical practice (Ulfvarson, Oxelmark, \& Jirwe, 2018). The sampling was purposive, and recruitment was made in two ways; either through a lecture about working hours led by the researchers, included in the hospitals' introduction programmes for nurses; or through information disseminated by the hospitals' HR departments. All nurses who signed up for the study $(\mathrm{N}=17)$ were contacted by e-mail or telephone in order to make an appointment for the interview. Eleven nurses answered and agreed to participate in the study (see Table 1).

The study was approved by the Regional Ethical Review Board in Stockholm (2016/139531/2). Before starting each interview participants gave written informed consent. It was emphasised that participation in the study was voluntary and that the participant could cancel the interview at anytime or choose not to answer some questions without giving further explanation. No compensation was given for participation. All data were stored on protected servers accessible only for researchers involved in the project.

\section{Materials}

Semi-structured interviews were conducted by either MS (female) or AD (female) and lasted approximately 45 minutes. The interviews were held between October 2016 and April 2017. The participants had not met the researcher before, apart from those who had attended the lecture at the introduction programme. Participants were told that the aim of the interview was 
to gain a deeper insight into the participant's work situation with focus on work hours and recuperation, in order to gain knowledge about how to design an intervention for newly graduated nurses. Interviews were conducted either by telephone (eight nurses) or face-to-face in the vicinity of the introduction programme (three nurses), focusing on sleep and fatigue in relation to shiftwork. No one but the participant and the researcher was present during the interview. The participants were told that the results would be presented at a group level only and that no individual answers would be communicated to managers. Specific questions addressed the nurses' experiences of sleep and fatigue in connection to different shifts (morning, evening, night and quick returns). Strategies used for recovery, such as managing sleep and fatigue when working the different shifts, were also explored. Also, more general questions like "do you experience sleep problems?”, "are you sometimes feeling fatigued or exhausted at work?” and "how do you recover during spare time?”, were used and complemented by appropriate follow-up questions. The questions were based on, and further developed from, a previous interview guide (Frögeli, Rudman, Ljótsson, \& Gustavsson, 2018). During the last interviews, no new information was identified and the research team considered data saturation to have been achieved in relation to the content of the data, i.e. when no new information was obtained from the interviews.

Sleepiness and fatigue can be described as two interrelated, but distinct, phenomena. Sleepiness could be broadly defined as the "drive" to fall asleep. Fatigue, on the other hand, could be defined as a subjective experience of overwhelming tiredness, lack of energy or exhaustion, that could be alleviated after rest, activity or stress management. However, the terms are commonly used interchangeably or merged under the broader term "tiredness" (Shen, Barbera, \& Shapiro, 2006). In this study, the term fatigue was used as a broader concept including also 'sleepiness' and 'tiredness', since it is likely that the participating nurses did not make any distinction when describing their experiences.

\section{Analysis}

All interviews were audio recorded, transcribed and analysed using inductive content analysis (Elo \& Kyngäs, 2008). The analysis was not software-assisted. The analysis process was conducted in three phases: preparation, organising and reporting.

In the preparation phase, the transcripts were read several times to make sense of the whole and units of analysis were selected. In this study, the unit of analysis was, as suggested by Graneheim and Lundman (2004), the interview as a whole. The data were then organised in three steps: open coding, creation of categories and abstraction. During the open coding, notes and headings were written in the text to describe all aspects of the content. The headings were then put into groups with similar content, and categories were generated. At the last step, abstraction, the subject under study was described by generating subcategories and naming them using content-characteristic words. The subcategories were grouped together into generic categories, and generic categories were grouped into wider main categories (see Table 2).

To increase the trustworthiness, the data collection, analysis and presentation of the results have involved a continuous process of discussions within the research group. The varied professional background and expertise in the research group was such that the researchers' pre-understandings were unlikely to affect data collection or analysis. Hence the risk of preconceived ideas and conclusions intruding was limited. Also, the questions asked during 
the interviews were open-ended and the respondents were asked to clarify their responses, so as to minimise reinterpretation of the answer by the interviewer. MJ has extensive knowledge and experience of qualitative research/analysis and guided the others in the research team. The analysis was initially conducted by $\mathrm{ME}$ and $\mathrm{AD}$, with and through regular discussions with MS and MJ, until common agreement was reached. In order to increase credibility of the results, MJ read all the interview transcripts and confirmed the analysis after it was completed. Many categories are exemplified with literal quotes from the nurses, which further increases the credibility. The article adheres to the consolidated criteria for reporting qualitative research (COREQ) checklist, see Supplementary File 1 (Tong, Sainsbury, \& Craig, 2007). 


\section{Results}

Analyses led to four main categories: 1) factors contributing to sleep problems, 2) strategies for sleep, 3) experiences of fatigue and 4) strategies for fatigue. Each main category consists of different generic categories, of which some consist of subcategories (Table 3).

\section{Factors contributing to sleep problems}

The analyses identified two generic categories characterizing the nurses' experiences of factors contributing to sleep problems: 1) shift factors and 2) cognitive arousal (with two subcategories).

\section{Shift factors}

Sleep quality was commonly discussed in relation to type of shift/shift sequence. Most nurses experienced impaired sleep quality in connection with shift combinations featuring an evening shift followed by a morning shift (hereafter referred to as 'quick returns'). While some stated that sleep between the evening and the morning shift was always bad, a few noted that high workload during the evening shift worsened subsequent sleep.

Also sleep duration was discussed in connection with shift sequence. The majority noted that quick returns were associated with shortened sleep duration. For many, the already short time available for sleep became even shorter due to difficulties unwinding, and consequently a longer sleep latency. A few also experienced shorter sleep duration before regular morning shifts.

The majority of nurses working night shifts expressed dissatisfaction with their sleep in relation to night work.

\section{Cognitive arousal}

Cognitive arousal was identified as an important cause of sleep problems, highlighted by most nurses. Worry or persistent thoughts in the evening, particularly related to work, often led to problems unwinding before sleep. This was especially common in relation to quick returns. Two main types of cognitive arousal were described: ruminative thinking and anticipatory stress. A majority noted that high workload during the previous or upcoming shift exacerbated rumination and anticipation processes, and worsened problems unwinding.

Ruminative thinking. Some nurses were often worrying or thinking about things that had happened at work, which impaired unwinding. This was, for example, expressed as persistent thoughts about a particular patient or worrying about not having done things correctly.

Thinking about everything and then winding down at home is incredibly difficult. The only thing buzzing around in my head is did I do the right thing, did I give the right medication, things like that, and then I dream about these things. (Nurse 3)

Anticipatory stress. In relation to quick returns, some respondents also reported that anticipatory stress, such as thinking or worrying about the next day's work, impeded unwinding. This was typically expressed as "thinking about what has to be done tomorrow" or as a feeling of already "being mentally at work the next day". Some respondents pointed out that merely thinking about the shorter time available for sleep was stressful. 
And if there's something in particular at work, you know you've got a lot of patients or some patients who sort of require a lot of attention, maybe that's something that you lie awake thinking about, and then sometimes you might not get to sleep until one or two in the morning. (...) And because you then have to get up so early the following morning, you start preparing for it and sort of start thinking about what you'll be doing during the day ahead. (Nurse 2)

\section{Strategies for sleep}

The analyses led to two generic categories of sleep strategies: 1) circadian rhythm and homeostasis, and 2) unwinding (with two subcategories).

\section{Circadian rhythm and homeostasis}

A few nurses reported they were trying to keep regular sleeping hours, and thus a stable circadian rhythm, despite irregular work hours. Others reported trying to adjust the circadian rhythm to their schedule, for example through preparing for a morning shift by getting up earlier in the mornings two days in advance, despite not working those mornings. Before night shifts, nurses reported strategies for rotating the rhythm forward by staying up late the preceding night, and then sleeping as long as possible in the morning before the night shift. When turning back to day or evening shifts after night work, two nurses described a strategy of setting the alarm earlier in the afternoon, to shorten the sleep and increase sleepiness in the evening.

\section{Unwinding}

Nurses used different unwinding strategies to facilitate sleep: 1) general unwinding and 2) detaching from work.

General unwinding. Before sleep, many nurses were undertaking behaviours aimed at unwinding and relaxation, such as listening to music, watching TV, having a shower, or using a breathing exercise. Some nurses described that they usually stayed up for a while after an evening shift, in order to unwind before bedtime, but avoided this during quick returns. However, two nurses used the strategy of staying up a while during quick returns; one had learned by experience that this made her sleep better.

In the beginning I think I tried to sort of go to bed as soon as I got home, but I realised that that wouldn't work. (...) I usually get home and, well, then perhaps I'll get something to eat or I'll lie down and read or watch TV. I wind down a bit and don't go to bed straight away. (...) Perhaps I'd get to sleep sooner if I went straight to bed, but I think maybe it would be slightly worse quality of sleep. (Nurse 10)

Detaching from work. Most nurses reported that they sometimes found it hard to detach from thoughts of work during leisure time and that this sometimes disturbed sleep. Different strategies were used to facilitate detachment. Some tried to distract themselves through focusing on other things, such as TV or mobile phone. Other strategies included just trying to think about something else and phoning a colleague. Some reported making a phone call from home to the ward, in order to ensure that everything was alright. One nurse had a strategy of telling her colleagues (before leaving work) to call her if something seemed unclear when she had left. Another had a strategy of writing reminders to herself while at home when she started thinking about things to do at work the next day. 
Two nurses usually experienced problems unwinding from thoughts of work during quick returns, and lacked strategies for handling it. Another nurse reported that she always lacked strategies when thoughts of work occupied her mind.

\section{Experiences of fatigue}

The experiences of fatigue consisted of two generic categories: 1) manifestations of fatigue (with three subcategories) and 2) temporal aspects.

\section{Manifestations of fatigue}

Three subcategories of fatigue manifestations were identified: cognitive, emotional and physical manifestations. The majority of the nurses highlighted that fatigue was more noticeable during certain periods of high workload. These were, for example, complex or highly emotional situations, bed crowding, or unexpected situations with many things happening at the same time. In contrast, some nurses experienced more fatigue during low workload or inactivity.

Cognitive manifestations. A majority of the nurses reported various kinds of cognitive manifestations of fatigue. Some experienced problems concentrating, for instance during shift handovers; others described memory difficulties, such as problems remembering the care plan or appointed times for medication. Also problems prioritising, making decisions or keeping track of the overall picture were described.

When you're calculating medication, or performing medical techniques, maybe taking samples, or when you really do have to focus a bit more. I can feel there's something missing. Then I can't focus as well, and I have to prepare a medication. And it's important not to make a mistake. (Nurse 9)

Emotional manifestations. Nurses also experienced emotional manifestations of fatigue, for example feelings of being more emotionally sensitive, more easily annoyed, unengaged, or not as happy as usual. Also, feelings of shame were reported in connection to fatigue.

It is hard to keep up with everything. I lose... I can forget what was planned for a patient if I'm tired, so I can forget the entire plan, even though we've done the rounds and have discussed and planned. If someone asks me something, I don't have a clue. (...) It's almost embarrassing, because you yourself think that you should know. (Nurse 1)

Physical manifestations. For some nurses, fatigue was also manifested in physical symptoms, like headache, dizziness, feeling cold or physically exhausted.

\section{Temporal aspects}

Fatigue varied with time of day, and was dependent on type of shift. In relation to morning shifts, many nurses described fatigue at the beginning of the shift, while others experienced more fatigue in the afternoon. During evening shifts, only a few nurses experienced fatigue. The majority described a period of severe fatigue during the early morning hours of the night shifts. Some also reported a sustained feeling of exhaustion following a night shift. During quick returns, while some nurses experienced fatigue at the beginning of the morning shift, the majority reported the most severe fatigue afterwards. 
It usually comes afterwards, that you're sort of struck that... Well, you become really tired. When I get home, I'm so tired that I could almost sleep sitting down. (Nurse 2)

\section{Strategies for fatigue}

Two generic categories of strategies for fatigue were identified in the analyses: 1 ) proactive and 2) reactive strategies. Proactive strategies were behaviours aimed at preventing fatigue, and reactive strategies were behaviours for coping with fatigue.

\section{Proactive strategies}

In order to prevent fatigue during morning shifts, some nurses described strategies related to sleep the preceding night. While some prioritised longer sleep in the morning instead of breakfast, others got up earlier in order to have time to "wake up" at home, or arrived early at work in order to have time to get started. One nurse, who could influence her schedule, usually planned an evening shift after a couple of consecutive morning shifts to enable a lie-in for recovery. In relation to evening shifts, some nurses reported having lie-ins in the morning before work in order to save energy and prevent fatigue.

Before an evening shift, I'll sleep almost the entire morning because I'm thinking that I have to cope at work. I really can't get anything done before work. It's probably more psychological, that if I do anything in the morning, like going and having lunch with someone or whatever, I think I'll be so tired when I get to work. (Nurse 1)

To prevent fatigue during the night shifts, most nurses reported resting or trying to have a nap in the daytime before the shift.

\section{Reactive strategies}

Various reactive strategies were reported aimed at coping with fatigue at work. One strategy was keeping active and being sure of having things to do at all times. One nurse had learned to ask for help when feeling tired. Another nurse said that she usually tried to pause for a minute and prioritise, make a plan, and then follow the plan. One nurse described that, when experiencing fatigue at work, she accepted it. Another reported that she sometimes stayed home from work due to fatigue.

I function best when I'm a bit stressed, because then I feel that I have to be doing something all the time - as soon as I have nothing to do, I'm finished. So I always try to find something. (Nurse 3)

Regarding strategies to handle accumulated fatigue after quick returns, some nurses went straight home after the morning shift and used the leisure time for resting. Other strategies included taking a nap when coming home and down-prioritising of physical activity or meeting up with friends.

\section{Discussion}

The aim of this study was to explore strategies used for managing sleep and fatigue problems, factors contributing to sleep problems, and the nature of fatigue problems, among newly graduated nurses. Results showed that new nurses sometimes lack effective strategies for addressing problems with sleep and fatigue. Furthermore, as discussed below, the results indicate that some strategies that were used may interfere with factors regulating sleep and 
wakefulness. High workloads were experienced as exacerbating cognitive arousal processes that disturb sleep, especially in relation to quick returns. Cognitive, emotional and physical manifestations of fatigue were described, and nurses often experienced severe fatigue after a quick return shift combination.

\section{Shift factors and cognitive arousal as contributing factors to sleep problems}

The results confirm previously observed associations between quick returns and poor sleep quality, longer sleep latency and shortened sleep duration (Vedaa et al., 2015; Dahlgren et al., 2016). They are also consistent with previous research that has identified cognitive arousal as a principal cause of disturbed sleep (Åkerstedt, 2006; Åkerstedt, Kecklund, \& Axelsson, 2007). Two main sleep disturbing cognitive processes emerged, ruminative thinking about previous work and anticipatory stress regarding work next day, both of which have previously been linked to disturbed sleep (Åkerstedt, 2006; Kecklund \& Åkerstedt, 2004). Problems with both ruminative thinking and anticipatory stress regarding work, during off-working hours, have also previously been described among newly graduated nurses (Duchscher, 2009).

A new finding was that these sleep-disturbing cognitive processes were especially common in relation to quick returns and were highlighted as being even bigger problems during high workload. Rumination and anticipation are plausible explanations of previous findings that quick returns are associated with problems unwinding and longer sleep latencies (Dahlgren et al., 2016, Vedaa et al., 2017). It is also possible that problems with unwinding and rumination exacerbate anticipation. However, previous studies have not examined how these processes are linked to workload and it should be explored further.

\section{Experiences of fatigue}

Most nurses reported severe fatigue after the morning shift ending a quick-return combination, while only some experienced fatigue during the actual shifts. A plausible explanation could be that stress activation, or keeping busy during work, masks underlying fatigue (Hockey, 2013) - a phenomenon which may also explain why some nurses described experiencing heightened fatigue during low workload. Notably though, fatigue was also experienced during high workload, which might indicate that the effects of underlying fatigue become more prominent during periods of increased demands that require higher executive functioning (Horne, 2012).

Fatigue was associated with a range of cognitive impairments such as problems concentrating and memorizing during important situations (e.g. shift handovers); and less effective executive functioning, such as difficulties prioritizing, making decisions, or keeping track of an overall plan. These results confirm previous laboratory findings and show how fatigue can affect patient safety (cf. Horne, 2012; Nilsson et al., 2005). Fatigue was also associated with emotional symptoms, which may be especially problematic for new nurses who start working in a profession where emotional management is often required (Delgado, Upton, Ranse, Furness, \& Foster, 2017). These findings highlight the nurses' need to adopt strategies for combating emotional and cognitive fatigue symptoms at work. Besides fatigue management strategies such as taking breaks (Hunter \& Wu, 2016), mindfulness-based techniques may also enhance the nurses' capacity for focused attention by focusing on present-moment awareness (Botha, Gwin, \& Purpora, 2015). 


\section{Sleep enhancing strategies and fatigue management}

The sleep enhancing strategies used by the nurses focused on the circadian and homeostatic aspects of sleep, and also on unwinding. Handling quick returns seemed to be the most problematic issue. Some nurses cut down or skipped time for unwinding before going to bed in order to maximise the available time for sleep. However, such a strategy may prolong sleep latency or impair sleep quality, due to a lingering stress activation. One nurse had learned that spending time unwinding before bedtime was worth-while, including during quick returns. Others reported not possessing any effective strategies for sleep and unwinding during quick returns, highlighting the vital need for support in this regard.

Persistent thoughts of work during leisure time can be seen as an indicator of not having mentally detached from work. Calling back to work from home in order to check up on things, or writing reminders to oneself at home regarding tomorrow's work, were examples of strategies used in order to detach or to reduce worry connected to work. Although such strategies may be functional in the short-term, they may not always be effective for reducing stress activation or worry in the long run (e.g. Barlow et al., 2011).

Remaining cognitively, and possibly also emotionally, engaged with stressful work events after finishing the shift continues to consume recourses and thus hampers recovery (Colombo \& Gallego, 2012). Difficulties with stopping thinking about work during free time has previously been associated with sleep problems (Åkerstedt et al., 2002) and clinical burnout (Söderström et al., 2012). This highlights the need for strategies that either prevent thoughts of work coming to mind during free time, or that help with detaching from them as they arise, e.g. one nurse had a strategy of always telling the colleagues to call her if something was unclear after she had left work.

Some strategies used for managing fatigue might interfere with factors regulating sleep. For example, having a lie-in in the morning before an evening shift, may contribute to problems falling asleep in the evening after the shift, especially during quick returns. Such a strategy may reduce the homeostatic drive for sleep, thereby inhibiting the initiation of sleep. This highlights the importance of encouraging behaviours that promote the sufficient build-up of homeostatic pressure before initiating sleep. Sleep-wake regularity are often encouraged in sleep hygiene programs (Stepanski \& Wyatt, 2003), but such a strategy can be hard or impossible to use while on shift work. Instead, the concept of 'anchor sleep' has been proposed, which means keeping at least 4 hours of sleep in a period of 24 hours at a fixed time, while the remaining sleep hours are taken irregularly. This strategy helps to synchronize circadian rhythms in the body and could also facilitate the building up of a homeostatic pressure (Minors \& Waterhouse, 1981) and is one that may be of importance in a sleep and recovery training programme for new nurses.

Coping with fatigue by keeping oneself active at work may prove to be counterproductive if it serves to maintain fatigue and stress, and contributes to unwinding and sleep problems. Thus it may be more beneficial to encourage nurses to engage in daily "recovery behaviours", such as taking breaks or using relaxation techniques, which have been shown to reduce stress and burnout symptoms (Lisspers, Almén, \& Sundin, 2014).

To cope with fatigue after quick returns, some nurses went straight home to rest after the morning shift and some down-prioritised social or physical activity those evenings. Although such behaviours may reduce immediate experiences of exhaustion, the restricted engagement 
in energizing or appetitive leisure activities may lead to increased exhaustion over time (Martell, Addis, \& Jacobson, 2001). It may be of value to encourage nurses strike a balance between spending time in passive rest and engaging in meaningful leisure activities.

Some nurses described fatigue management strategies that are consistent with ergonomic recommendations, such as trying to maintain a stable rhythm regardless of working shifts, or having a rest or nap before the night shift (Kecklund \& Axelsson, 2016). Although all the nurses had limited experience of working as a nurse, previous work experience may explain why some had, and some had not, developed strategies for sleep and fatigue. Accordingly, an early awareness of short- and long-term effectiveness in coping with sleep and fatigue in relation to shiftwork, and how strategies interact with factors regulating sleep, would be beneficial.

In sum, many new nurses experienced a lack of effective strategies for handling sleep and fatigue. Therefore, a specially tailored educative programme for new nurses that promotes the use of effective recovery strategies is suggested. Such a program could incorporate techniques from cognitive behavioural therapy and mindfulness-based techniques, with the aims of enhancing sleep, strengthening daily recovery, promoting unwinding from work-related stress and reducing rumination about work during leisure time (Sonnentag \& Fritz, 2007; Colombo \& Cifre Gallego, 2012; Manber \& Carney, 2015; Botha, Gwin, \& Purpora, 2015).

Some limitations of this study should be noted. First, a relatively small study sample was used. However, despite the sample size, the nurses' experiences were quite similar. Secondly, nurses who experience more sleep or fatigue problems are the ones most likely to participate in a study that addresses these themes. However, the results are in many ways similar to previous studies about sleep, fatigue and shiftwork. Since nurses from different hospitals and wards were interviewed, and their experiences were generally consistent, the results are likely to be transferable to other settings including newly graduated nurses.

\section{Conclusion}

This study showed that newly graduated nurses often experience sleep difficulties and problems with fatigue at work. In particular, recovery connected to quick returns was impaired. Many nurses also lacked effective strategies for managing sleep and fatigue when they started working. Moreover, some strategies used for sleep and fatigue may interfere with circadian and homeostatic factors regulating sleep, while strategies aimed at unwinding are not always experienced as effective, particularly regarding quick returns.

Sleep hygiene education and interventions based on cognitive behavioural therapy have been proposed as joint strategies for the prevention of sleep and fatigue problems among shift workers (Järnefelt et al., 2012; Richter, Acker, Adam, \& Niklewski, 2016). The experiences described by participants in this study suggest that newly graduated nurses would probably benefit from a specially tailored sleep and recovery programme. Such an intervention should preferably target effective strategies related to both sleep regulating processes (i.e. circadian and homeostatic factors) and stress-related factors (Åkerstedt, 2003; Linton et al., 2015). More specifically, it could include themes such as: routines and techniques for unwinding before bedtime; strategies for preventing, or detaching from, thoughts of work during leisure time; behaviours that promote the build-up of homeostatic pressure for initiating sleep and the maintenance of stable circadian rhythms; behaviours promoting recuperation during the day; 
strategies for combating cognitive and emotional fatigue at work; and the promotion of active and meaningful leisure time (Manber \& Carney, 2015; Morin, 1993; Shapiro, Astin, Bishop, \& Cordova, 2005).

\section{Relevance to clinical practice}

Sleep and fatigue problems are common among nurses and may have consequences for both patient safety and the nurses' own health. This study highlights the importance of addressing these issues in nursing education and work introduction programmes, and suggests specific strategies and behaviours that could be targeted in a sleep programme tailored for newly graduated nurses.

\section{What does this paper contribute to the wider global clinical community?}

- Newly graduated nurses lack effective strategies for sleep and fatigue, and the strategies used are often counterproductive.

- Newly graduated nurses experience cognitive deficits due to fatigue, which may have implications for patient safety.

- Newly graduated nurses need to learn effective strategies for managing sleep and fatigue, in order to promote patient safety and nurses' health. 
Åkerstedt, T. (2003). Shift work and disturbed sleep/wakefulness. Occupational Medicine, 53, 89-94. https://doi.org/10.1093/occmed/kqg046

Åkerstedt, T. (2006). Psychosocial stress and impaired sleep. Scandinavian Journal of Work, Environment \& Health, 32, 493-501. https://doi.org/10.5271/sjweh.1054

Åkerstedt, T., Kecklund, G., \& Axelsson, J. (2007). Impaired sleep after bedtime stress and worries. Biological Psychology, 76, 170-173.

https://doi.org/10.1016/j.biopsycho.2007.07.010

Åkerstedt, T., Knutsson, A., Westerholm, P., Theorell, T., Alfredsson, L., \& Kecklund, G. (2002). Sleep disturbances, work stress and work hours: A cross-sectional study. Journal of Psychosomatic Research, 53, 741-748. https://doi.org/10.1016/S0022-3999(02)00333-1

Barlow, D.H., Farchione, T.J., Fairholme, C.P., Ellard, K.K., Boisseau, C.L., Allen, L.B., \& Ehrenreich-May, J. (2011). Unified protocol for transdiagnostic treatment of emotional disorders: Therapist guide. New York: Oxford University Press.

Botha, E., Gwin, T., \& Purpora, C. (2015). The effectiveness of mindfulness based programs in reducing stress experienced by nurses in adult hospital settings: a systematic review of quantitative evidence protocol. JBI Database of Systematic Reviews and Implementation Reports, 13, 21-29. https://doi.org/10.11124/jbisrir-2015-2380

Brosschot, J. F., Gerin, W., \& Thayer, J. F. (2006). The perseverative cognition hypothesis: A review of worry, prolonged stress-related physiological activation, and health. Journal of Psychosomatic Research, 60, 113-124. https://doi.org/10.1016/j.jpsychores.2005.06.074

Colombo, V., \& Cifre Gallego, E. (2012). The importance of recovery from work: A review of where, how and why. Papeles del Psicólogo, 33, 129-137.

Dahlgren, A., Kecklund, G., \& Åkerstedt, T. (2005). Different levels of work-related stress and the effects on sleep, fatigue and cortisol. Scandinavian Journal of Work, Environment \& Health, 31, 277-285. http://doi.org/10.5271/sjweh.883

Dahlgren, A., Tucker, P., Gustavsson, P., \& Rudman, A. (2016). Quick returns and night work as predictors of sleep quality, fatigue, work-family balance and satisfaction with work hours. Chronobiology International, 33, 759-767.

https://doi.org/10.3109/07420528.2016.1167725

Dawson, D., \& McCulloch, K. (2005). Managing fatigue: It's about sleep. Sleep Medicine Reviews, 9, 365-380. https://doi.org/10.1016/j.smrv.2005.03.002

Delgado, C., Upton, D., Ranse, K., Furness, T., \& Foster, K. (2017). Nurses’ resilience and the emotional labour of nursing work: An integrative review of empirical literature.

International Journal of Nursing Studies, 70, 71-88.

https://doi.org/10.1016/j.ijnurstu.2017.02.008

Duchscher, J. E. B. (2009). Transition shock: the initial stage of role adaptation for newly graduated Registered Nurses. Journal of Advanced Nursing, 65(5), 1103-1113.

https://doi.org/10.1111/j.1365-2648.2008.04898.x

Elo, S., \& Kyngäs, H. (2008). The qualitative content analysis process. Journal of Advanced Nursing, 62, 107-115. https://doi.org/10.1111/j.1365-2648.2007.04569.x 
Frögeli, E., Rudman, A., Ljótsson B., \& Gustavsson, P. (2018). Preventing stress-related ill health among newly registered nurses by supporting engagement in proactive behaviors: development and feasibility testing of a behavior change intervention. Pilot and Feasibility Studies, 4, 28. https://doi.org/10.1186/s40814-017-0219-7

Geurts, S., \& Sonnentag, S. (2006). Recovery as an explanatory mechanism in the relation between acute stress reactions and chronic health impairment. Scandinavian Journal of Work, Environment and Health, 32, 482-492.

Graneheim, U.H., \& Lundman, B. (2004). Qualitative content analysis in nursing research: concepts, procedures and measures to achieve trustworthiness. Nurse Education Today, 24, 105-112. https://doi.org/10.1016/j.nedt.2003.10.001

Hasson, D., \& Gustavsson, P. (2010). Declining sleep quality among nurses: A populationbased four-year longitudinal study on the transition from nursing education to working life. PLoS One, 5(12), e14265. https://doi.org/10.1371/journal.pone.0014265

Hockey, R. (2013). The Psychology of Fatigue: Work, Effort and Control. Cambridge: Cambridge University Press.

Horne, J. (2012). Working throughout the night: Beyond 'sleepiness' - impairments to critical decision making. Neuroscience \& Biobehavioral Reviews, 36, 2226-2231.

https://doi.org/10.1016/j.neubiorev.2012.08.005

Hughes, R.G., \& Rogers, A.E. (2004). Are you tired?: Sleep deprivation compromises nurses' health—and jeopardizes patients. American Journal of Nursing, 104, 36-38.

Hunter, E. M., \& Wu, C. (2016). Give Me a Better Break: Choosing Workday Break Activities to Maximize Resource Recovery. Journal of Applied Psychology, 101, 302-311. https://doi.org/10.1037/apl0000045

Järnefelt, H., Lagerstedt, R., Kajaste, S., Sallinen, M., Savolainen, A., \& Hublin, C. (2012). Cognitive behavioral therapy for shift workers with chronic insomnia. Sleep Medicine, 13(10), 1238-1246. https://doi.org/10.1016/j.sleep.2012.10.003

Kecklund, G., \& Åkerstedt, T. (2004). Apprehension of the subsequent working day is associated with a low amount of slow wave sleep. Biological Psychology, 66, 169-176. https://doi.org/10.1016/j.biopsycho.2003.10.004

Kecklund, G., \& Axelsson, J. (2016). Health consequences of shift work and insufficient sleep. BMJ, 355, i5210. https://doi.org/10.1136/bmj.i5210

Linton, S. J., Kecklund, G., Franklin, K. A., Leissner, L. C., Sivertsen, B., Lindberg, E., ... Hall, C. (2015). The effect of the work environment on future sleep disturbances: A systematic review. Sleep Medicine Reviews, 23, 10-19. https://doi.org/10.1016/j.smrv.2014.10.010

Lisspers, J., Almén, N., \& Sundin, Ö. (2014). The Effects of a Recovery-Focused Program for Stress Management in Women-An Exploratory Study. Health, 6, 2825-2836. https://doi.org/10.4236/health.2014.620321 
Manber, R., \& Carney, C. (2015). Treatment plans and interventions for insomnia: a case formulation approach. New York: The Guilford Press.

Martell, C.R., Addis, M.E., \& Jacobson, N.S. (2001). Depression in context: Strategies for guided action. New York: W. W. Norten \& Company.

McDowall, K., Murphy, E., \& Anderson, K. (2017). The impact of shift work on sleep quality among nurses. Occupational Medicine, 67, 621-625. https://doi.org/10.1093/occmed/kqx152

McEwen, B. S. (2004). Protection and Damage from Acute and Chronic Stress: Allostasis and Allostatic Overload and Relevance to the Pathophysiology of Psychiatric Disorders. Annals of the New York Academy of Sciences, 1032(1), 1-7. https://doi.org/10.1196/annals.1314.001

McEwen, B. S. (2006). Sleep deprivation as a neurobiologic and physiologic stressor: allostasis and allostatic load. Metabolism, 55, 20-23.

https://doi.org/10.1016/j.metabol.2006.07.008

McVicar, A. (2003). Workplace stress in nursing: a literature review. Journal of Advanced Nursing, 44, 633-642. https://doi.org/10.1046/j.0309-2402.2003.02853.x

Minors, D.S., \& Waterhouse, J.M. (1981). Anchor sleep as a synchronizer of rhythms on abnormal routines. International Journal of Chronobiology, 7, 165-88.

Morin, C. M. (1993). Insomnia: Psychological assessment and management. New York: Guilford Press.

Nilsson, J. P., Söderström, M., Karlsson, A. U., Lekander, M., Åkerstedt, T., Lindroth, N. E., \& Axelsson, J. (2005). Less effective executive functioning after one night's sleep deprivation. Journal of Sleep Research, 14, 1-6. https://doi.org/10.1111/j.13652869.2005.00442.x

Richter, K., Acker, J., Adam, S., \& Niklewski, G. (2016). Prevention of fatigue and insomnia in shift workers-a review of non-pharmacological measures. The EPMA Journal, 7, 16. https://doi.org/10.1186/s13167-016-0064-4

Rudman, A., \& Gustavsson, J. P. (2011). Early-career burnout among new graduate nurses: A prospective observational study of intra-individual change trajectories. International Journal of Nursing Studies, 48, 292-306. https://doi.org/10.1016/j.ijnurstu.2010.07.012

Shapiro, S. L., Astin, J. A., Bishop, S. R., \& Cordova, M. (2005). Mindfulness-Based Stress Reduction for Health Care Professionals: Results From a Randomized Trial. International Journal of Stress Management, 12, 164-176. https://doi.org/10.1037/1072-5245.12.2.164

Shen, J., Barbera, J., \& Shapiro, C.M. (2006). Distinguishing sleepiness and fatigue: focus on definition and measurement. Sleep Medicine Reviews, 10, 63-76.

https://doi.org/10.1016/j.smrv.2005.05.004

Söderström, M., Jeding, K., Ekstedt, M., Perski, A., \& Åkerstedt, T. (2012). Insufficient sleep predicts clinical burnout. Journal of Occupational Health Psychology, 17, 175-183.

https://doi.org/10.1037/a0027518 
Sonnentag, S., \& Fritz, C. (2007). The Recovery Experience Questionnaire: Development and Validation of a Measure for Assessing Recuperation and Unwinding From Work. Journal of Occupational Health Psychology, 12, 204-221. https://doi.org/10.1037/1076-8998.12.3.204

Stepanski, E.J., \& Wyatt, J. K. (2003). Use of sleep hygiene in the treatment of insomnia. Sleep Medicine Reviews, 7, 215-225. https://doi.org/10.1053/smrv.2001.0246

Sun, Q., Ji, X., Zhou, W., \& Liu, J. (2019). Sleep problems in shift nurses: A brief review and recommendations at both individual and institutional levels. Journal of Nursing Management, 27, 10-18. https://doi.org/10.1111/jonm.12656

Tong, A., Sainsbury, P., \& Craig, J. (2007). Consolidated criteria for reporting qualitative research (COREQ): A 32-item checklist for interviews and focus groups. International Journal for Quality in Health Care, 19, 349-357. https://doi.org/10.1093/intqhc/mzm042

Ulfvarson, J., Oxelmark, L., \& Jirwe, M. (2018). Assessment in clinical education: A comparison between a generic instrument and a course-specific criterion-based instrument. Nordic Journal of Nursing Research, 38, 220-226. https://doi.org/10.1177/2057158518768404

Vedaa, Ø., Harris, A., Bjorvatn, B., Waage, S., Sivertsen, B., Tucker, P., \& Pallesen, S. (2015). Systematic review of the relationship between quick returns in rotating shift work and health-related outcomes. Ergonomics, 59, 1-14.

https://doi.org/10.1080/00140139.2015.1052020

Vedaa, Ø., Mørland, E., Larsen, M., Harris, A., Erevik, E., Sivertsen, B., ... Pallesen, S. (2017). Sleep detriments associated with quick returns in rotating shift work: A diary study. Journal of Occupational and Environmental Medicine, 59, 522-527.

https://doi.org/10.1097/JOM.0000000000001006 
Table 1. Background information about participants.

\begin{tabular}{|l|l|l|l|l|l|}
\hline Participant & Gender & Age & Workplace & $\begin{array}{l}\text { Employment as } \\
\text { nurse (months) }\end{array}$ & Shift schedule \\
\hline 1 & Female & 29 & Geriatrics & 4 & Morning and evening \\
\hline 2 & Male & 26 & Psychiatry & 4 & Morning, evening and night \\
\hline 3 & Female & 35 & Stroke & 4 & Morning and evening \\
\hline 4 & Female & 25 & Infection & 9 & Morning, evening and night \\
\hline 5 & Female & 29 & Palliative care & 5 & Morning and evening \\
\hline 6 & Female & 27 & Missing & 4 & Morning and evening \\
\hline 7 & Female & 24 & Infection & 11 & Morning, evening and night \\
\hline 8 & Female & 51 & Rehabilitation & 5 & Morning and evening \\
\hline 9 & Female & 22 & Neonatal care & 5 & Morning, evening and night \\
\hline 10 & Female & 26 & Patient hotel & 12 & Morning, evening and night \\
\hline 11 & Female & 26 & Hand surgery & 12 & 4 \\
\hline
\end{tabular}


Table 2. Example of coding and categorisation.

\begin{tabular}{|c|c|c|c|c|}
\hline Data from interviews & Codes from interviews & Subcategory & Generic category & Main category \\
\hline $\begin{array}{l}\text { It's harder when I'm on an evening-day shift, but of course this is about winding } \\
\text { down, but I find it harder to switch off from work when I get home. I just think, I } \\
\text { have to do this tomorrow, and this, and this, and this ... That doesn't happen when } \\
\text { I'm on day-day shifts, because then I can let go in a different way. (Nurse 4) }\end{array}$ & $\begin{array}{l}\text { Hard to switch off, thinking } \\
\text { about what has to be done } \\
\text { tomorrow }\end{array}$ & \multirow{2}{*}{$\begin{array}{l}\text { Anticipatory } \\
\text { stress }\end{array}$} & \multirow{4}{*}{ Cognitive arousal } & \multirow{4}{*}{ Factors contributing to sleep problems } \\
\hline $\begin{array}{l}\text { Mainly if you've been working an evening shift and then you have to work in the } \\
\text { day. Then I find, well, I always sleep really badly. So it's a bit like, you feel that } \\
\text { you sleep and then you have to get back to work, and if it was a busy night you sort } \\
\text { of know," I can't forget that", and things pop up in my head, like there are certain } \\
\text { things you have to do. (Nurse 7) }\end{array}$ & $\begin{array}{l}\text { Things that I have to do the } \\
\text { next day pop up in my head }\end{array}$ & & & \\
\hline $\begin{array}{l}\text { Thinking about everything and then winding down at home is incredibly difficult. } \\
\text { The only thing buzzing around in my head is did I do the right thing, did I give the } \\
\text { right medication, things like that, and then I dream about these things. (Nurse 3) }\end{array}$ & $\begin{array}{l}\text { Things like "did I do the right } \\
\text { thing”, "did I give the right } \\
\text { medication" are buzzing } \\
\text { around in my head }\end{array}$ & \multirow{2}{*}{$\begin{array}{l}\text { Ruminative } \\
\text { thinking }\end{array}$} & & \\
\hline $\begin{array}{l}\text { If you compare with my previous workplace, that's a bit why I resigned from my } \\
\text { previous workplace, because it was such an incredibly stressed workplace. And } \\
\text { there I sort of felt that it was almost impossible to wind down, because there was so } \\
\text { much happening during the days, and you weren't sure, did I do everything I was } \\
\text { supposed to do. (Nurse 11) }\end{array}$ & $\begin{array}{l}\text { It was almost impossible to } \\
\text { unwind, I was not sure if I } \\
\text { had done everything I was } \\
\text { supposed to }\end{array}$ & & & \\
\hline
\end{tabular}


Table 3. Newly graduated nurses’ sleep and fatigue experiences and strategies.

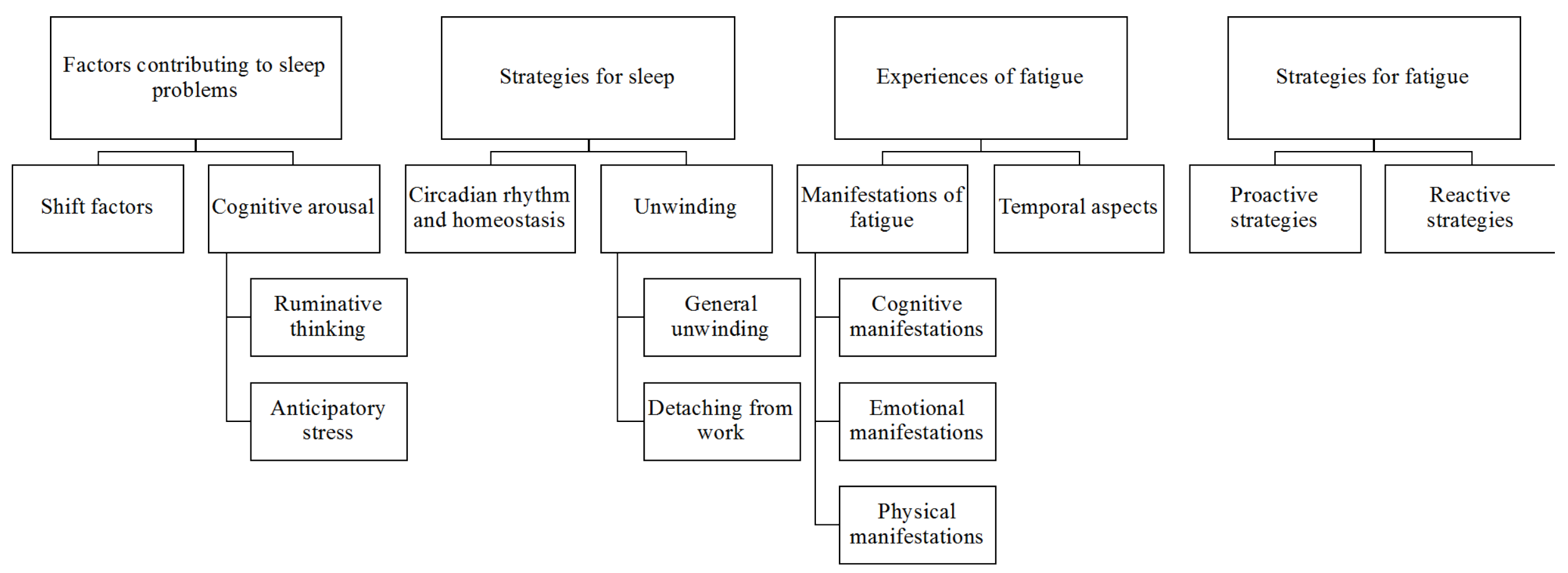

